NOTICE: this is the author's version of a work that was accepted for publication in WEAR. Changes resulting from the publishing process, such as peer review, editing, corrections, structural formatting, and other quality control mechanisms may not be reflected in this document. Changes may have been made to this work since it was submitted for publication. A definitive version was subsequently published in WEAR, Vol. 304, no. 1-2 (2013). DOI: http://dx.doi.org/10.1016/j.wear.2013.04.008 


\title{
Machinability study of first generation duplex (2205), second generation duplex (2507) and austenite stainless steel during drilling process
}

\author{
J. Nomani, A. Pramanik*, T. Hilditch, G. Littlefair \\ School of Engineering, Deakin University, Waurn Ponds, Australia \\ Department of Mechanical Engineering, Curtin University, Bentley, WA, Australia
}

\begin{abstract}
Machinability tests were conducted on duplex alloys SAF 2205 and SAF 2507, while employing austenite stainless steel 316L as a benchmark during drilling. Tool wear, cutting forces and machined surface finish were compared and analysed under similar machining conditions. Both duplex alloys displayed poorer machinability responses, with 2507 being worst. Abrasion and adhesion are the most common wears appeared on the flank and rake faces. Adhesion wear being the most severe on the flank face, is seen to be triggered by built-up edge formation. Duplex alloys 2507 and 2205 both show a higher response to built-up edge formation. Flute damage on the drill tools found during drilling of both duplex alloys can cause tool failure. Higher machining force and worse surface finish were found for second generation duplex (2507).
\end{abstract}

Keywords: duplex stainless steel, machinability, flute damage, tool wear, built-up edge

\section{Introduction}

Stainless steel consumption has increased year-on-year worldwide at a compound rate of 5\% over the last 20 years; more than other metals [1]. Duplex stainless steels, which were originally developed in the 1920's [2], are becoming ever more mainstream materials with increasing applications in the marine, industrial, construction and chemical processing industries. Duplex alloys are desirable engineering materials and offer significant beneficial features, such as, corrosion resistance, high tensile strengths and relative low cost due to lower contents of nickel and molybdenum [3-5]. The lower cost feature of duplex is particularly significant when considering its application in highly corrosive environments where other materials providing similar performance are significantly more expensive. Furthermore, due to the high strength compared to the 300 series, 
duplex stainless steels are increasingly used as an alternative material to austenitic stainless steel [68].

The superior mechanical properties of duplex stainless steel originates from a 1:1 matrix of austenite $(\gamma)$ and ferrite $(\alpha)$ phases presenting in a banded structure as depicted in Fig. 1 where the lighter phase is austenite and the darker phase is ferrite. The $\gamma$ phase is responsible for the relative ductility and resistance to uniform corrosion; while the $\alpha$ phase is responsible for the superior strength as well as corrosion resistance [9]. Both phases exist in relatively large separate volumes and in approximately equal fractions rather than an inclusion phase embedded in the matrix formed by one of the other phases [10].

Stainless steels in general are regarded as difficult to machine materials due to their high tendency to work harden; their toughness and relatively low thermal conductivity [11-15]. Other problems stem from their high fracture toughness, which increase tool/chip interface temperatures leading to poor surface finish and poor chip breaking. Furthermore, built-up-edge (BUE) formation is present even at elevated cutting speeds. This deteriorates the finish of the machined surface and increases the cutting forces [16]. The duplex alloys are more difficult to machine than the austenitic grades though these have better mechanical properties. The common basis for its poor machining behaviour stem primarily from the resulting high strength of the alloy but being exacerbated by lack of non-metallic inclusions and the low carbon content $[4,17]$. However, there is still a deficient understanding in machining of duplex stainless steel. Investigating the material response during machining processes is a general strategy to understand the machinability of any material. These also provide insight to what are the essential questions, and draw out key areas requiring central focus. There are some studies to investigate machinability of duplex alloys. Paro et al., [14] drilled HIPed P/M super duplex Duplok 27 and conventionally-produced A8910 1A stainless steels. They established a correlation between the pitting resistance equivalent (PRE) [18], and the machinability of duplex alloys. A duplex with higher PRE value gives worse tool life. The PRE of HIPed P/M Duplok 27 stainless steel is $25 \%$ higher than the PRE-value of cast A890 1A stainless steel thus tool life during drilling HIPed P/M Duplok 27 stainless steel is 40\% shorter than that of cast A890 1A stainless steel. Moreover, it was revealed that tool wear in drilling, using TiN-coated cemented carbide drills with through coolant, increased continuously at lower cutting speeds. The plastic deformation of the cutting edges became a limiting factor leading ultimately to flaking of the coating at higher speeds. The micro hardness of both phases present in the chip also increased as the cutting speed increased. 
Carlborg et al., [22] considered four duplex and one high alloyed austenitic steels during turning process to compare the performance of cemented carbide cutting tool. Their investigation was limited to qualitative discussion on tool wear and quantitative discussion on tool life. There was no information on machining forces or surface integrity.

Having said these, there is no study on drilling of second generation duplex alloy (SAF 2507) so far in the literature. In addition, a comparison of machinability among the first generation duplex, second generation duplex and austenitic stainless steel are also missing. Though these are imperatively needed to optimise the application and improve the productivity of these materials. This paper compares and investigates the machinability of duplex SAF 2205, super-duplex SAF 2507 and $316 \mathrm{~L}$ austenitic stainless steel in terms of cutting forces and surface roughness with advancement of tool wear (qualitative and quantitative) during drilling process.



Fig. 1 Typical "banded" duplex stainless steel microstructure (50x)

\section{Experimental details}

\section{$2.1 \quad$ Workpiece materials}

Duplex SAF 2205, super-duplex SAF 2507 and 316L austenitic stainless steels are workpiece materials in this investigation. The chemical compositions and basic mechanical properties of the three workpiece materials are given in table 1 . Wrought specimens were $20 \mathrm{~mm}$ in diameter for both duplex grades and $25 \mathrm{~mm}$ in diameter for the austenitic grade.

\begin{tabular}{|c|c|c|c|c|c|c|c|c|c|c|c|c|}
\hline Alloy & $\mathbf{C}$ & $\mathbf{M n}$ & $\mathbf{S i}$ & $\mathbf{S}$ & $\mathbf{P}$ & $\mathbf{N i}$ & $\mathbf{C r}$ & $\mathbf{M o}$ & $\mathbf{F e}$ & $\begin{array}{c}\text { UTS } \\
(\mathbf{M P a})\end{array}$ & $\begin{array}{c}\text { Yield } \\
\mathbf{( M P a )}\end{array}$ & $\begin{array}{c}\text { Hardness } \\
\mathbf{H V}_{\mathbf{1 0 0 g}}\end{array}$ \\
\hline SAF 2507 & 0.02 & 0.74 & 0.23 & 0.01 & 0.02 & 6.77 & 25.1 & 3.68 & Balance & 866 & 570 & 285 \\
\hline SAF 2205 & 0.02 & 0.8 & 0.4 & 0.01 & 0.02 & 5.2 & 22.4 & 3.05 & Balance & 777 & 556 & 279 \\
\hline
\end{tabular}




\begin{tabular}{|l|l|l|l|l|l|l|l|l|l|l|l|l|}
\hline AISI 316L & 0.03 & 1.5 & 0.4 & 0.03 & 0.03 & 10.5 & 17 & 2.1 & Balance & 640 & 326 & 254 \\
\hline
\end{tabular}

Table 1 Chemical composition and mechanical properties of the workpiece materials.

\subsection{Experimental procedure}

Drilling experiments were performed on a Haas (XYZ) Super VF-3 CNC vertical machining centre using $12 \mathrm{~mm}$ diameter Seco SD203A-M geometry drills, these were TiAIN + TiN coated solid carbide twist drills with internal coolant supply. General purpose emulsion type mineral oil based cutting fluid with a dilution concentration of $5 \%$ was supplied at a continuous flow rate of $9.91 / \mathrm{min}$. Machining parameters for all the drilling trials comprised a cutting speed of $60 \mathrm{~m} / \mathrm{min}$; a penetration rate of $0.15 \mathrm{~mm} / \mathrm{rev}$; and a hole depth of $30 \mathrm{~mm}$ continuous. A Kistler $9257 \mathrm{~b}$ cutting force dynamometer coupled with a Kistler 16-channel charge amplifier was used to measure the reaction forces as well as the torque during drilling. Readings were data-logged on computer using 'Dynaware' cutting force software. The experimental setup is shown in Fig. 2. The workpiece was mounted in a special fixture that was located rigidly on the centre of the dynamometer platform - i.e. equi-spaced between the four quartz crystals. Tool wear on the flank face was measured at regular intervals using an optical microscope. Drilling continued until a tool wear value $\left(V B_{\max }\right)$ of $0.15 \mathrm{~mm}$ was reached or until tool failure. The surface roughness of machined surfaces of each workpiece was recorded using a stylus measurement device, namely a Talysurf Intra Series 50.

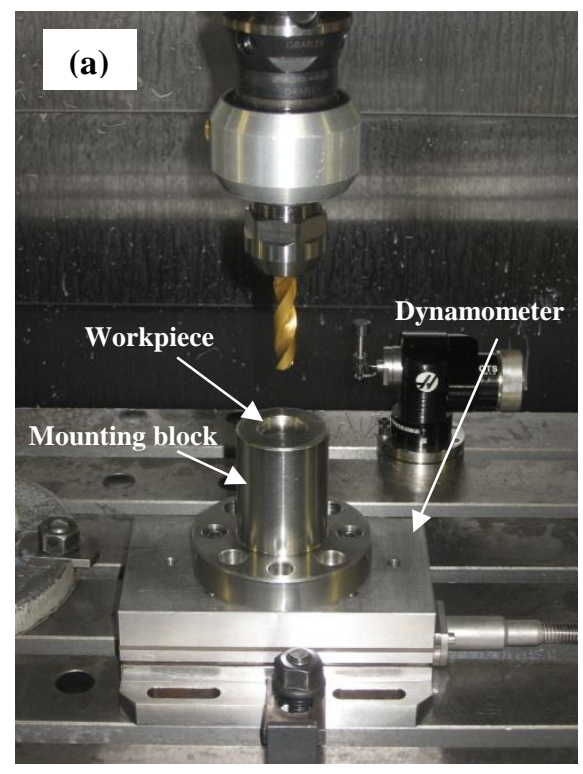

(b)

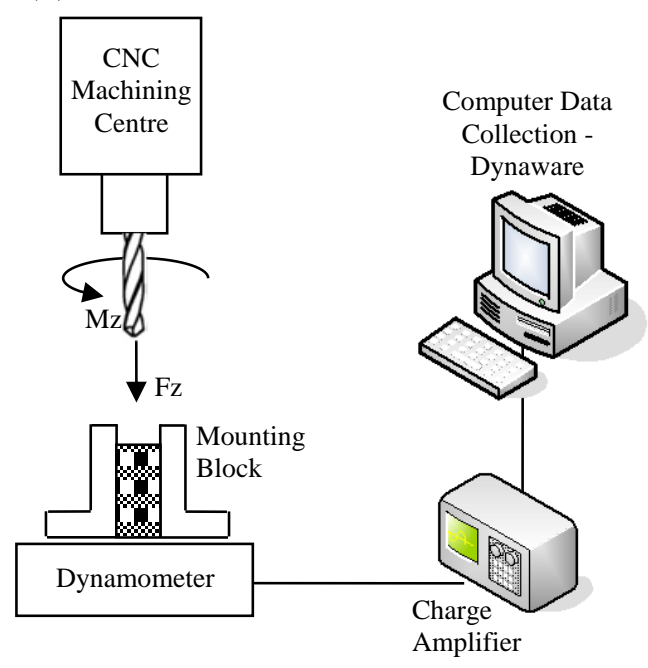

Fig. 2 (a) Drilling experimental setup (b) Schematic diagram of experimental setup 


\section{Results and discussion}

\subsection{Tool wear}

Different areas, such as, flank face, rake face, chisel edge and all over the flute, of the carbide drill tools were examined for wear/damage. The amount of wear of the tool was dependant on the degree of contact and interaction with the workpiece material. However, in all cases, the amount of wear was found to vary with the workpiece materials. These are described in the following sections.

\subsubsection{Flank wear}

Fig. 3 shows the progression of maximum flank wear with the number of drilled holes for the three workpieces. The rate of flank wear was very high for the second generation duplex (2507). It reached to the set flank wear criterion after drilling 26 holes. The rate of flank wear development for the drilling of the first generation duplex (2205) was less than that of second generation duplex (2507) from at the start until $40^{\text {th }}$ hole. But the wear stabilised after that. Though the drill tool wear remained below the set criterion, the tool failed after drilling 69 holes. Severe damage in the flute was noted approximately $10 \mathrm{~mm}$ above the drill tip as shown in Fig. 4. This damage resulted may be from higher cutting loads and poor chip evacuation. The rate of tool wear during machining of the austenite $316 \mathrm{~L}$ (Fig. 3) was very low initially (until $15^{\text {th }}$ hole) then it stabilizes (until $35^{\text {th }}$ hole). After that the wear rate increased (until $55^{\text {th }}$ hole) and then stabilized again. In this case, the drill tool succeeded in maintaining acceptable flank wear and without tool failure until drilling 75 holes.

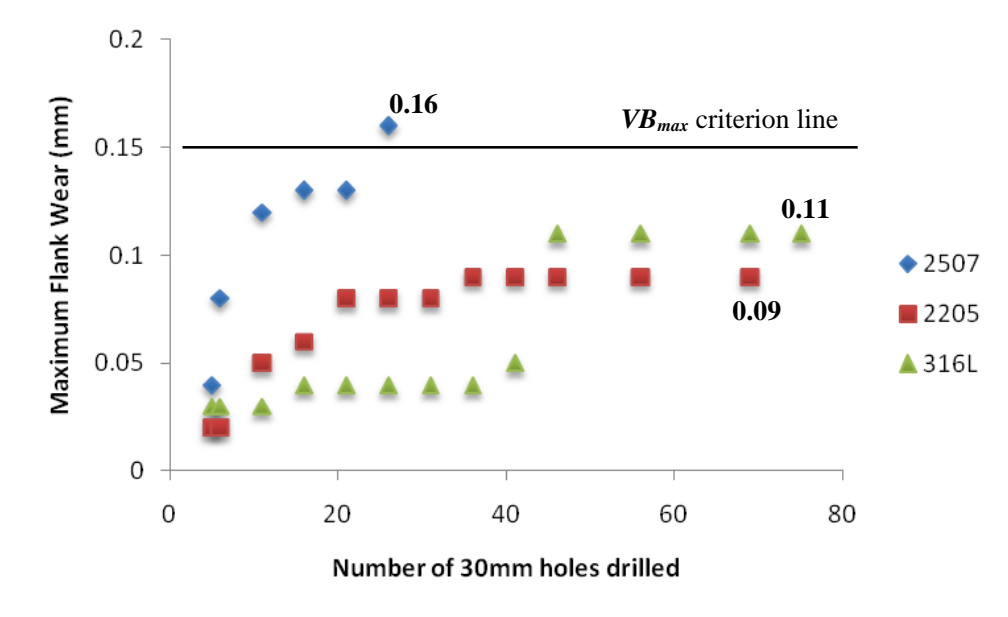

Fig.3 Maximum flank wear during drilling of duplex SAF 2507, SAF 2205 and Austenite 316L. 


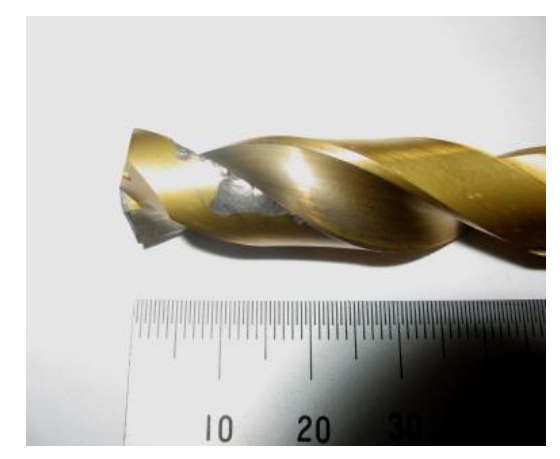

Fig. 4 Flute damage after drilling 69 holes in SAF 2205.

The micrographs of wear progression on the flank face are presented in Fig. 5. After drilling 6 holes, frittering and flaking are visible under microscope for all the three materials. These are mainly caused by resulting abrasion wear generated from sliding between the cutting lip and the chip material flow. Overall, the damage caused by abrasion wear was seen as minor, despite its wide appearance to surround the cutting edge perimeter.

With the progress of drilling the presence of built-up edge on the flank face became frequent for both duplex alloys, shown around the mid stage images in Fig. 5. In this figure, the flank wear for drilling of duplex SAF 2507 is presented only at $6^{\text {th }}, 15^{\text {th }}$ and $26^{\text {th }}$ holes as the cutting tool damaged after drilling $26^{\text {th }}$ hole. Thus, the cutting tool performance is worst for drilling duplex SAF 2507 and is not comparable to that of duplex SAF 2205 and austenite 316L. The presence of built-up edge triggers the adhesion wear, causing damage to the flank surface. In monitoring the flank wear of the duplex drills, it was found that the higher $V B_{\max }$ are directly caused by adhesion wear. The $V B_{\max }$ are highlighted on the flank face in the images in Fig. 5. Austenite 316L responded with less severity to built-up edge in comparison, resulting to minimal flank wear.

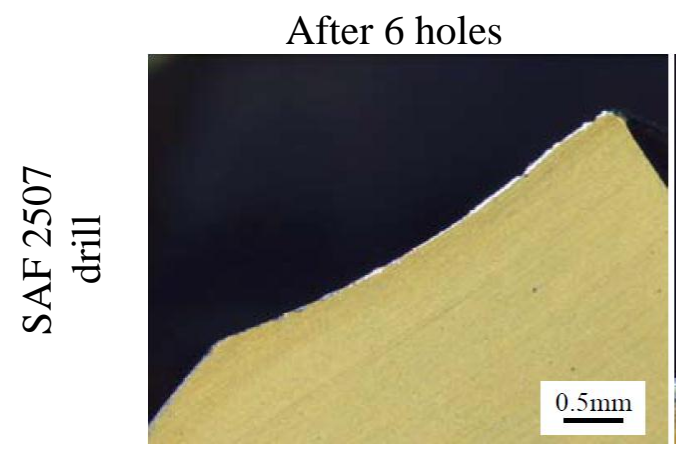

After 6 holes

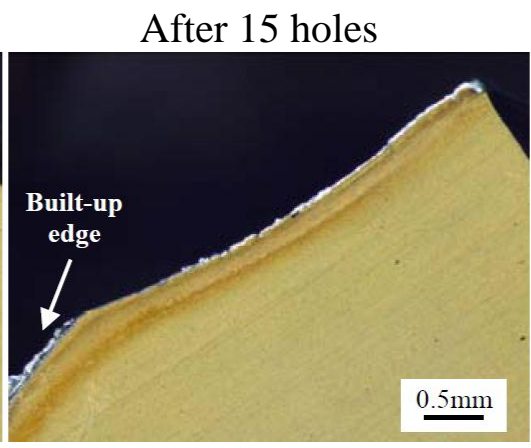

After 36 holes

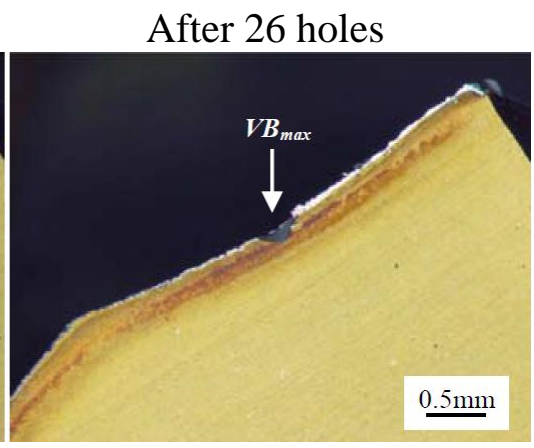

After 69 holes 


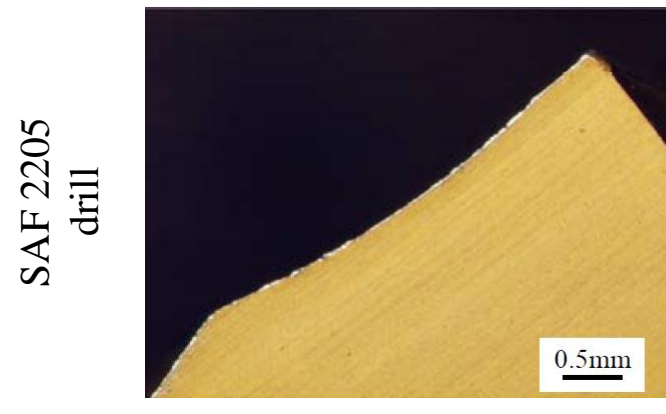

After 6 holes

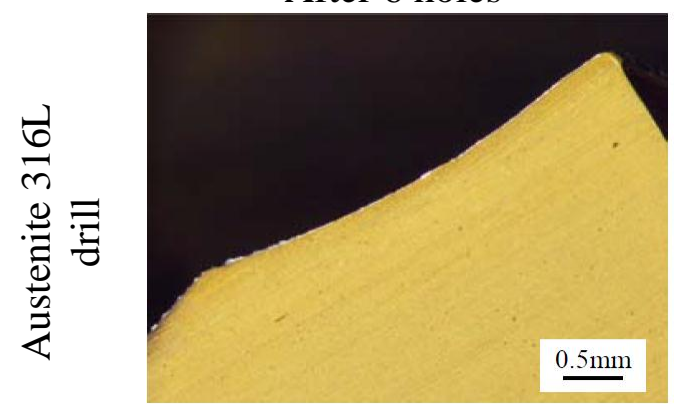

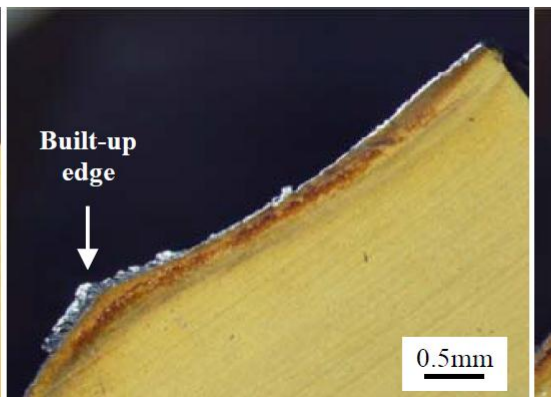

After 36 holes

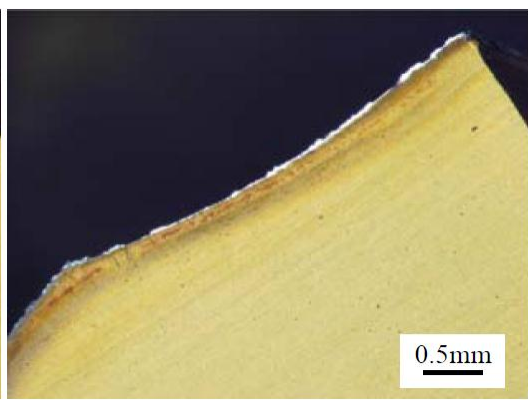

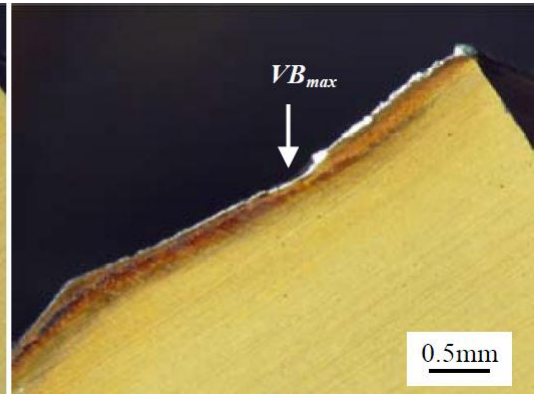

After 75 holes

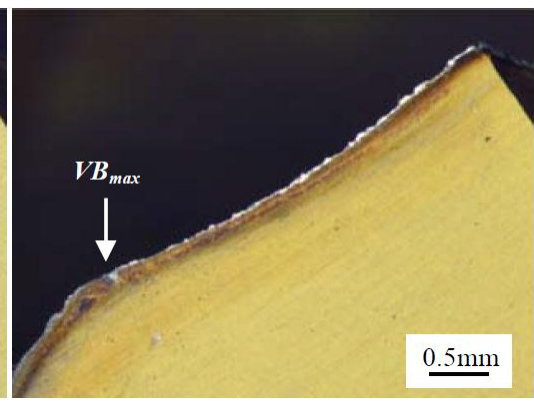

Fig. 5 Micrographs of the flank face at different stages during drilling different materials (16x)

The micrographs in Fig. 6 illustrate adhesion wear triggered by the formation of built-up edge. Bonding occurs between the hardened built-up material layer and the drill cutting lip (carbide material). At a certain stage with further drilling, the shearing action removes the built-up edge layer while simultaneously detaching a region of the cutting lip by a plucking type action. This leaves behind cavities in the drill tool.
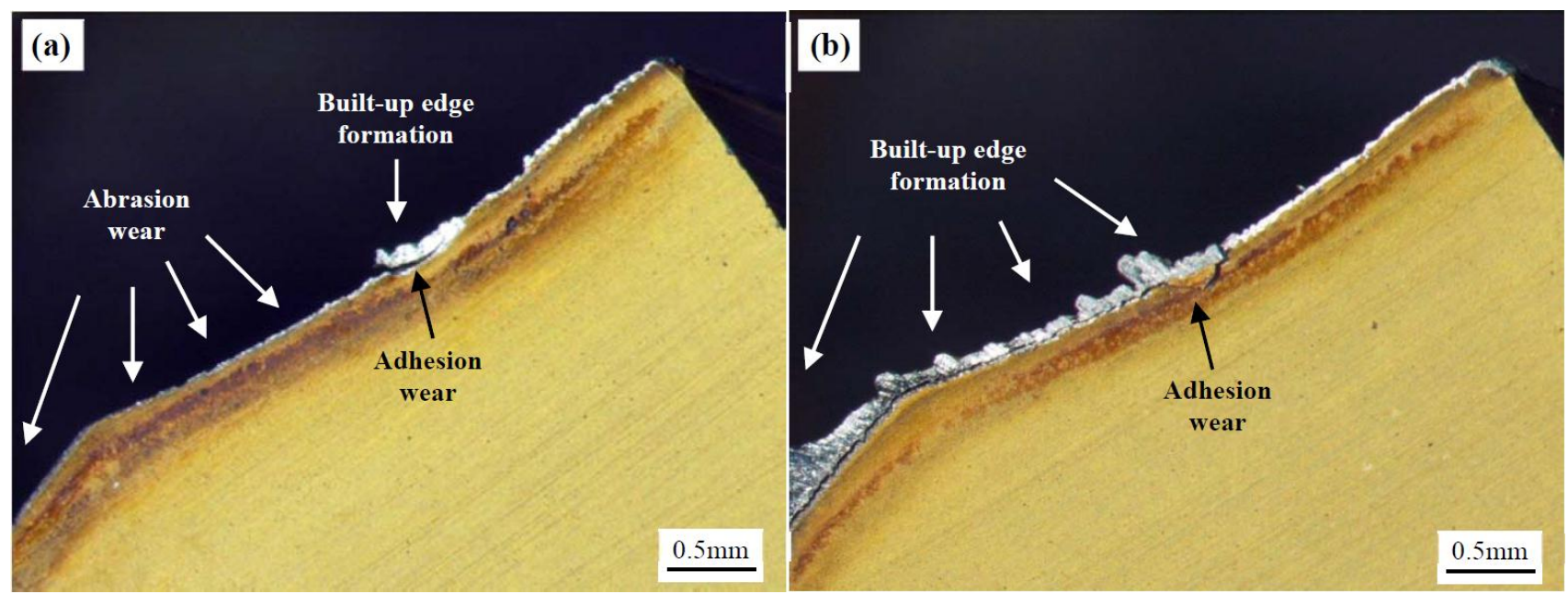

Fig. 6 Built-up edge formation on the flank face of a drill tool, triggering adhesion wear in drilling (a) SAF 2205 and (b) SAF 2507 
Built-up edge is frequently mentioned through various papers tied to machining duplex [14, 19-24]. The established account of built-up edge is caused by material work-hardening and the natural high tendencies for adhesion seen in machining duplex. M'Saoudi [25] shows single phase materials including austenite $316 \mathrm{~L}$ undergoes higher concentrations of work-hardening compared to 2205 duplex in machining. This would suggest austenite 316L showing higher rates of built-up edge than duplex grades, which was not the case in the present work. Carlborg [22] suggested a relation between the amount of built-up edge and the amount of ferrite phase in duplex. Although the relation remains questionable, with the microstructure and mechanism detail yet to be presented, Williams and Rollason [26] showed supporting work, observing a correlation between the size of built-up edge and the increasing amount of second phase in turning carbon steels. Further, it was suggested that a second phase in the material promotes an additional fracture point occurring at the secondary shear zone between the chip and the tool rake face, promoting stability to the formation of a built-up edge.

\subsubsection{Rake wear}

The rake face is heavily scoured for all materials as shown in the micrographs in Fig. 7. Abrasion appears as the dominant wear mechanism due to severe friction occurring from machined chip travelling down the rake face. This removes coating and layers of carbide from the tool rake face. After 6 holes, drill tools for duplex are more worn compared to that of austenite 316L. Adhesion is also evident from the layers and fragments of built-up edge bonding to the rake face, matching similar observations made by Paro et al., [14] with drilling cast duplex. Similar to flank wear, more adhesion wear found on the duplex tool rake faces compared to austenite 316L. The corner round radius of the rake face had seen little change throughout drilling tests, for all the cases.

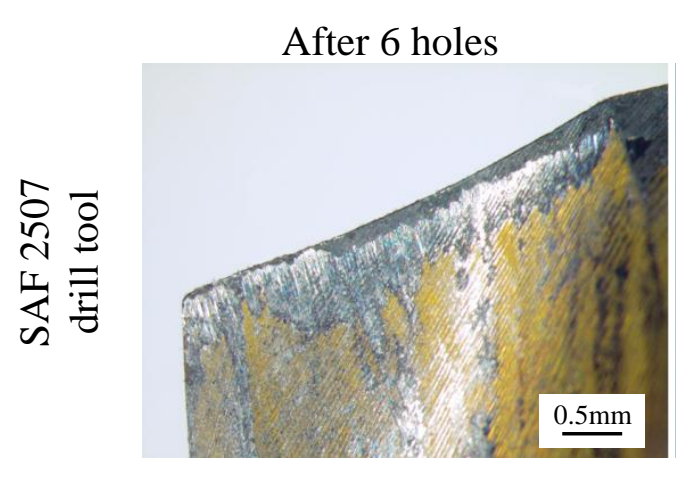

After 6 holes

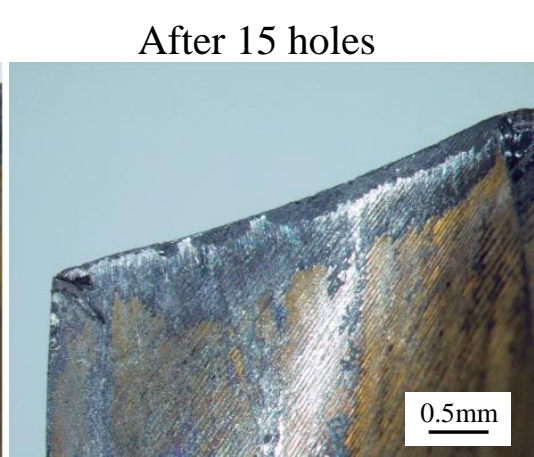

After 36 holes
After 26 holes

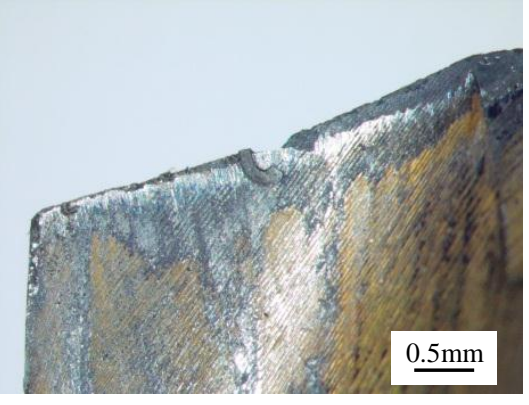

After 69 holes 


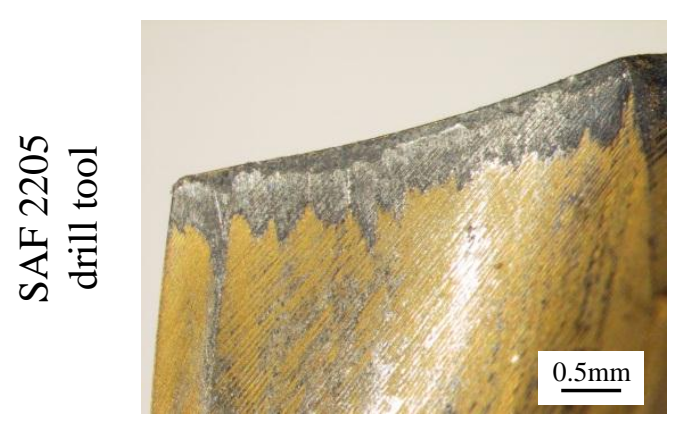

After 6 holes

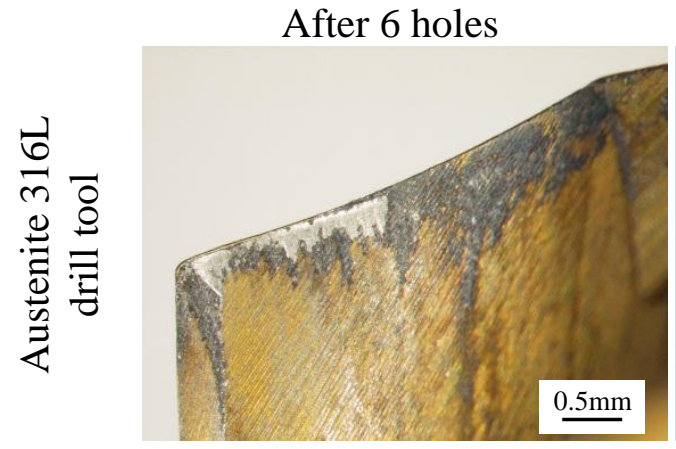

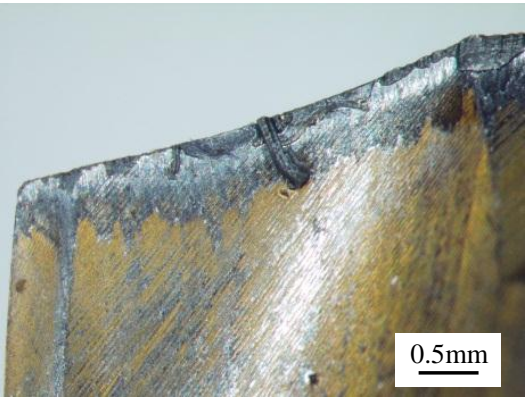

After 36 holes

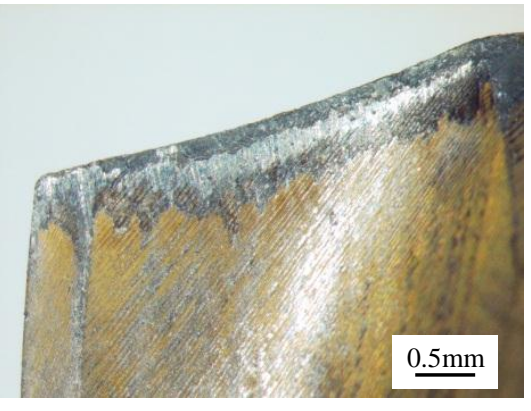

After 75 holes

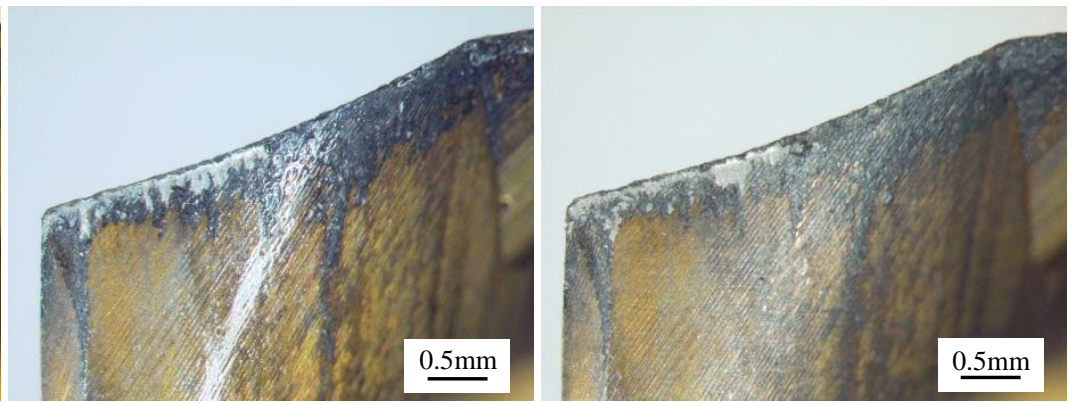

Fig. 7 Micrograph images of the rake face of drill tools during the progression of drilling trials.

\subsubsection{Chisel edge wear}

The condition of the chisel edge is important, since it is responsible for surface penetration and consumes over $50 \%$ of the total thrust load [27]. A damaged chisel edge can result to cutting load increase and lateral vibration at the entrance [28]. Micrographs in Fig. 8 demonstrate that the chisel edges of tools for duplex alloys are more affected by wear. Crater type cavities corresponding to fatigue wear appear on both duplex drills, the largest appearing for duplex 2507, measured at 0.24 $\mathrm{mm}$. For duplex 2205, the tool appears to have suffered a fracture, first appearing after drilling 30 holes. After fracture, the chisel edge was observed at regular intervals. It was found that the fractured cavity promotes formation of built-up edge as shown in Fig. 9. This resulted further growth in the cavity by adhesion, as the built-up edge layer was removed from further cutting. The chisel edge on the austenite $316 \mathrm{~L}$ tool mostly remains unaffected by abrasion and adhesion wears, at most, causing chipping and flaking on the chisel edge. Surprisingly, it was found the thrust load experienced during the surface penetration by chisel edge was higher in the case of austenite $316 \mathrm{~L}$ compared to both duplex alloys, as highlighted in Fig. 10. 

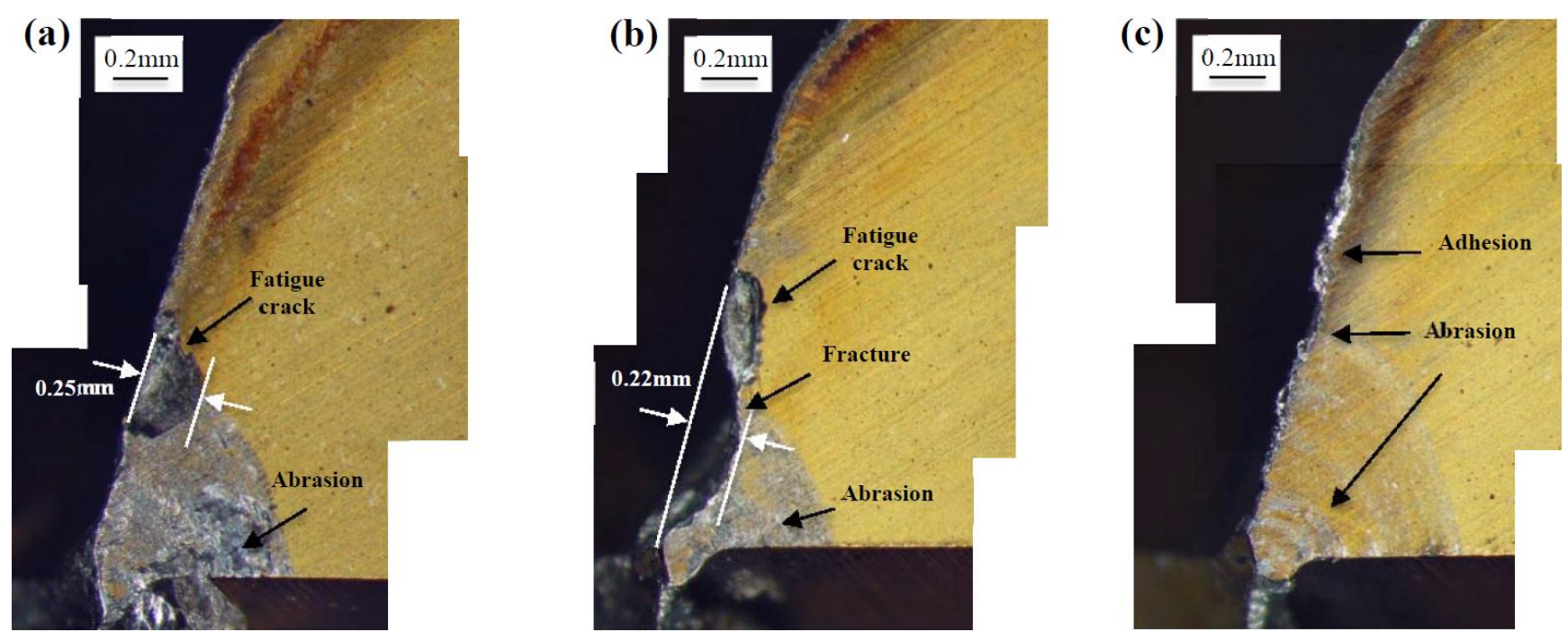

Fig. 8 Wear on chisel edge of drill tools after cutting materials (a) 2507 after 26 holes (b) 2205 after 69 holes (c) 316L after 75 holes.

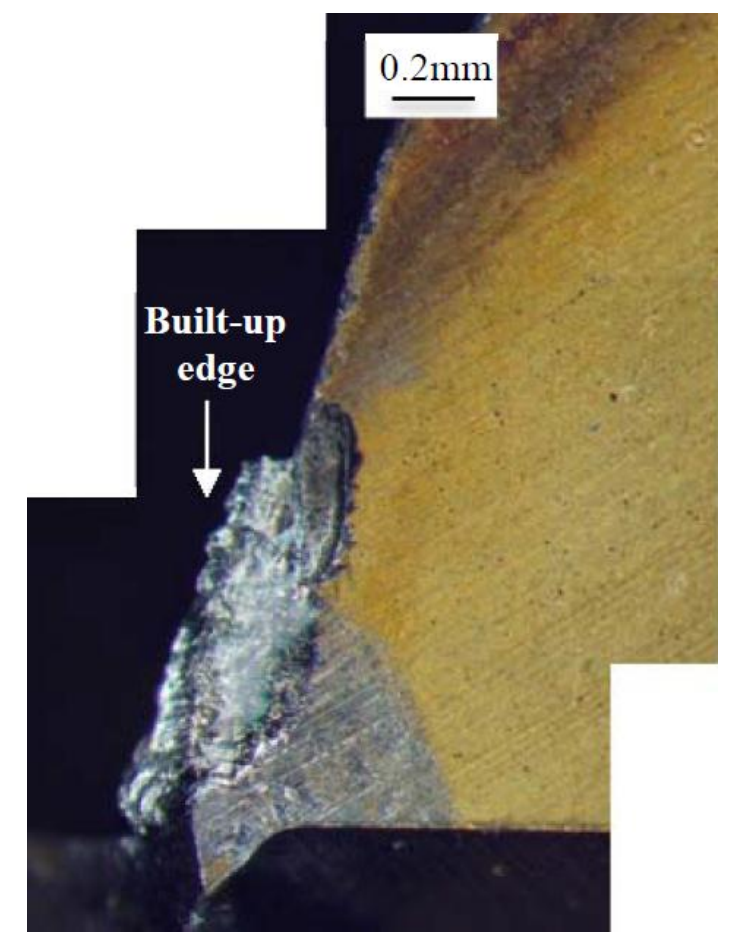

Fig. 9 Built-up edge layer imbedded in chisel edge cavity of 2205 drill tool after 46 holes of drilling 


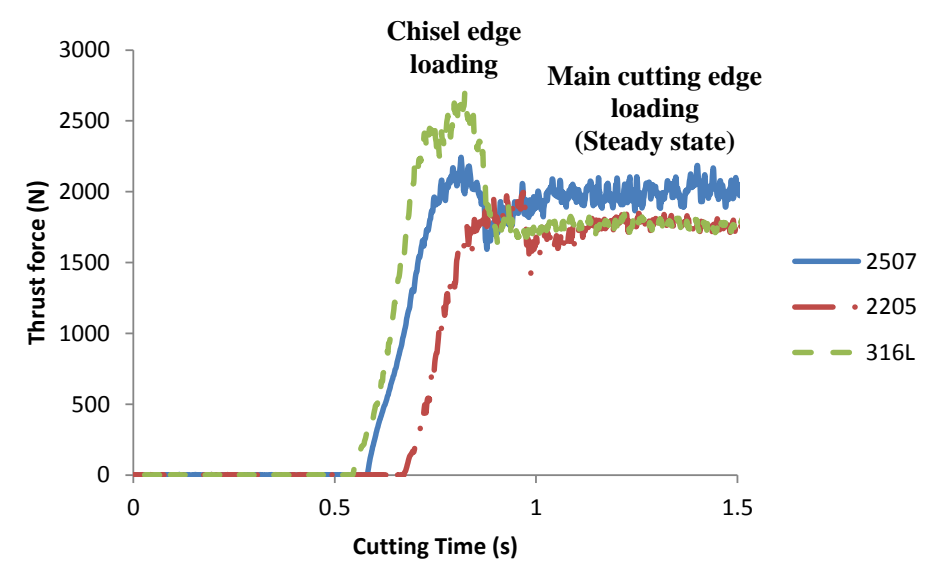

Fig. 10 Thrust force monitoring during surface penetration of the chisel edge.

\subsubsection{Flute damage}

The wear in the upper sections of flute of drill tools was found only in the drilling of duplex alloys 2507 and 2205. For drilling duplex 2507, the tool developed flute wear of $2 \mathrm{~mm}$ wide cavity after drilling the $6^{\text {th }}$ hole, as shown in Fig 11. Between the duration of drilling tests (26 holes) the size of the wear cavity remained similar, however new cavities developed in other areas of the similar shape and size. With the type of drill tool being a hardened carbide material, the nature of the fracture is irreversible and brittle.

Flute wear for duplex 2205 developed at a more gradual rate. First visible indications occurred after the $17^{\text {th }}$ hole, producing a smaller wear cavity compared to the 2507 drill tool. The size of the flute wear region remained the same until drilling reached the $65^{\text {th }}$ hole. The growth of the existing wear cavity increased to over double its size. Upon the drilling of the $68^{\text {th }}$ hole, a large rupture occurred underneath the existing wear region. The enlarged damaged region ultimately resulted in tool failure. SEM images of the flute damage area are shown in Fig. 12. It reveals fatigue fracture characteristics, evident by progressions or 'beachmark' lines similar to fatigue fracture. Cyclic loading from thermal or torsional stresses during drill rotation and the presence of two dissimilar phases in the material can be considered as the cause of fatigue. The primary origin of the fracture was traced back to the flute edge of the tool.
After 6 holes
After 21 holes
(new wear development)
(new wear development)
After 26 holes
(same and existing wear
development) 

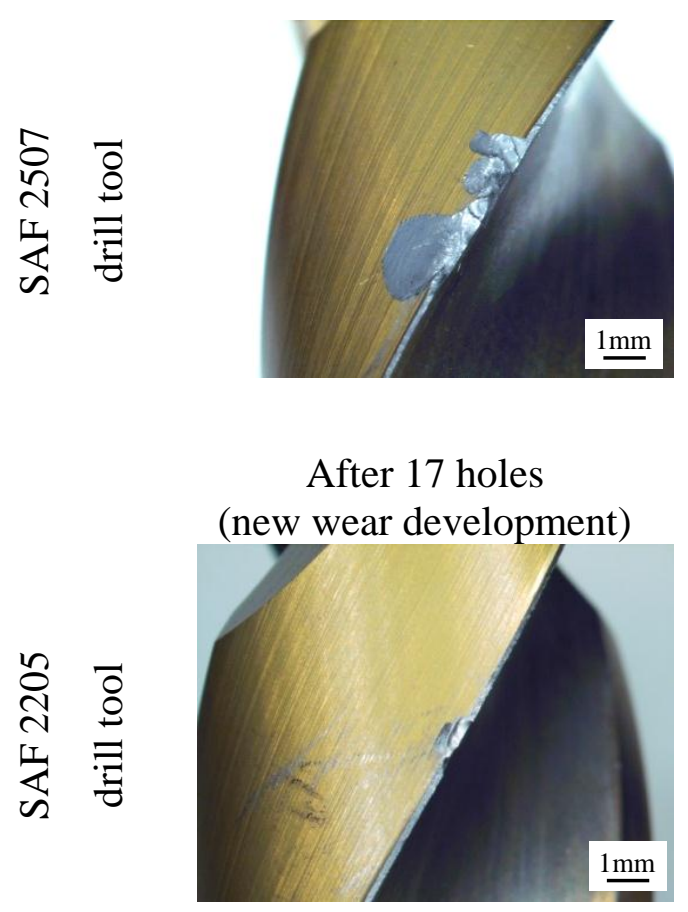

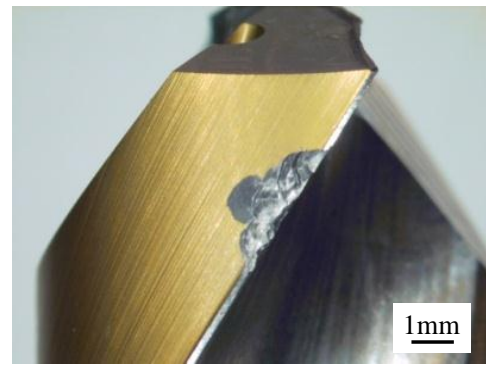

After 65 holes (growth of existing wear development)

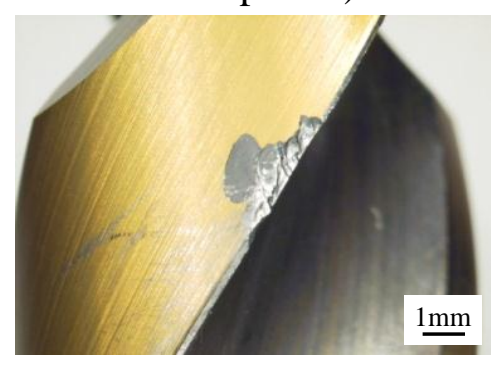

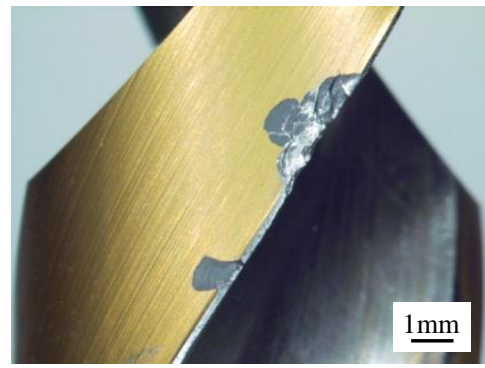

After 68 holes (growth of existing wear region)

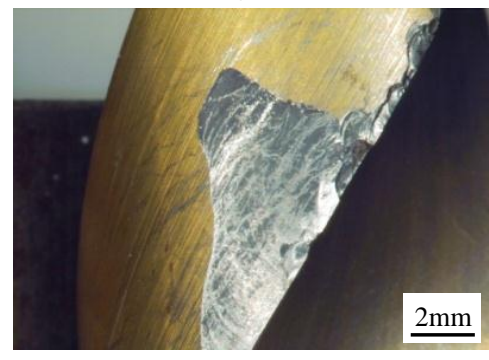

Fig. 11 Flute wear morphology on solid carbide tools during drilling SAF 2507 and SAF 2205
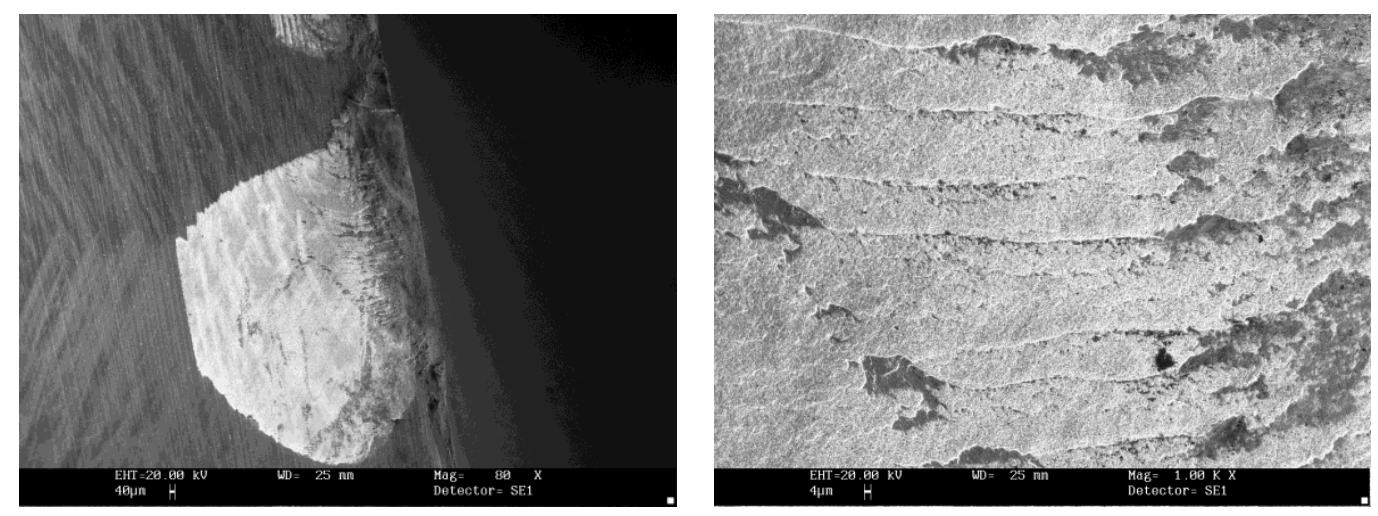

Fig. 12 SEM image of (a) flute wear (b) magnified area showing beachmark progression lines

The main indication for tool failure was the responsive high cutting loads, indicated by the power load increase monitored at the $\mathrm{CNC}$ terminal, and the output drilling torque measured by the dynamometer. Fig. 13 displays the drilling torque profile of the $69^{\text {th }}$ hole with the tool affected by the flute wear damage, compared with a normal torque profile (described in the next section) taken at an earlier stage. The comparison shows the affected flute wear damage having a profound effect on the cutting torque. The torque load rapidly increased during thrust movement of the drill, and peaked when the drill reached its designated drilling depth $(30 \mathrm{~mm})$. A torque load was also present while the drill was retracting, clearly undesirable and uncommon. The resulting torque behaviour was caused by poor chip evacuation. The normal conical helical chips produced, had become mangled, 
producing undesirable transitional and folded chip segments. The flute damage creates an issue with machined chips travelling up the spiral flute channel.

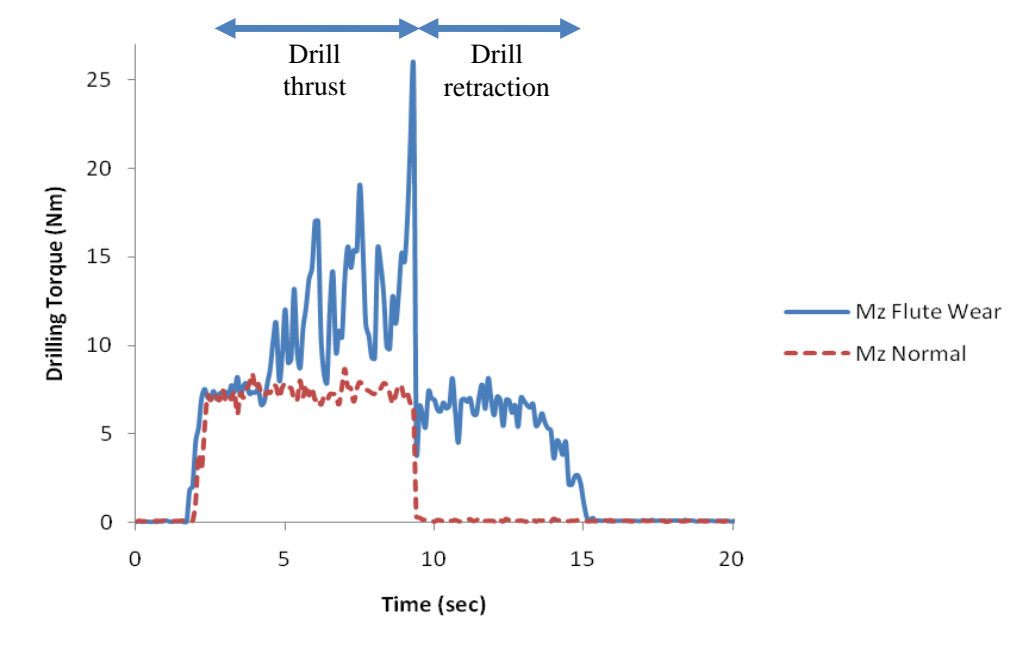

Fig. 13 Cutting torque profiles showing the impact of flute damage during the drilling of SAF 2205

It is well known that sulphur and phosphorous compounds lubricates and protects the cutting tool from wear. These improve the performance of coolant. It seems that higher sulphur and phosphorous content of austenite 316L compare to that of duplex 2507 and 2205 (table 1)may be responsible for better tool performance during drilling austenite $316 \mathrm{~L}$.

\subsection{Cutting forces}

Average thrust forces for different workpiece materials are presented in Fig. 14a. Higher force is noted for duplex 2507 and indicates that this material is harder to cut, sequentially followed by austenite $316 \mathrm{~L}$ and duplex 2205. The order did not correlate to material hardness or mechanical strength values as it would suggest. Jiang [12] reported a similar force comparison in the grinding of the same materials. Duplex 2205 had a lower grinding force compared to austenite 316L. The effect of tool wear on force is shown by the increasing trend in average thrust force, particularly for duplex 2205 and austenite 316L. Fig. 14b shows the thrust force profiles for a single hole. The initial high peak displayed by austenite 316L shows stronger resistance to surface penetration, as previously mentioned in section 3.1.3. After surface penetration, when the main cutting edges initiate cutting, its thrust force reduces and remains constant, achieving steady state. Duplex 2507 displayed a higher steady state range after surface penetration, and remaining unchanged until the drilling depth was 
reached. In contrast, the thrust profile for duplex 2205 is shown to gradually decrease while in steady state cutting.

Measuring the torque provided a general indication of power consumption, since power in drilling is the product of torque and the rotational speed of the drill. Thus average torque and comparison of torque profiles in Fig. 15 shows both duplex alloys require more cutting power to drill, compared to austenite 316L. The rampant increase of average torque displayed by duplex 2205 at the closing experimental stages, illustrates the severe effect of flute wear damage experienced by the tool.

(a)

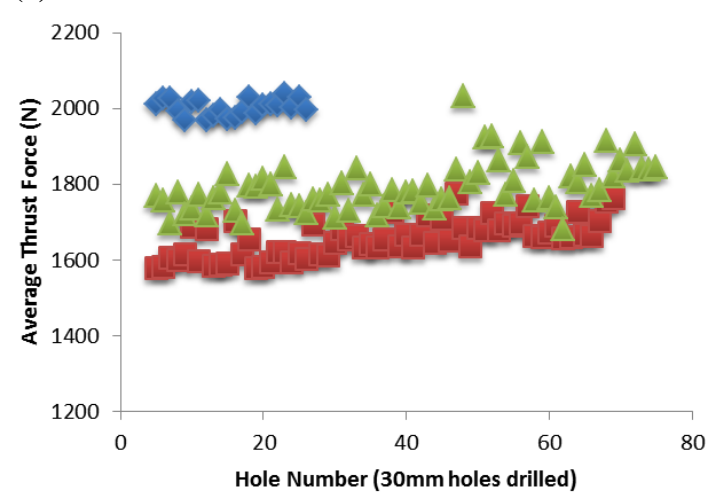

(b)

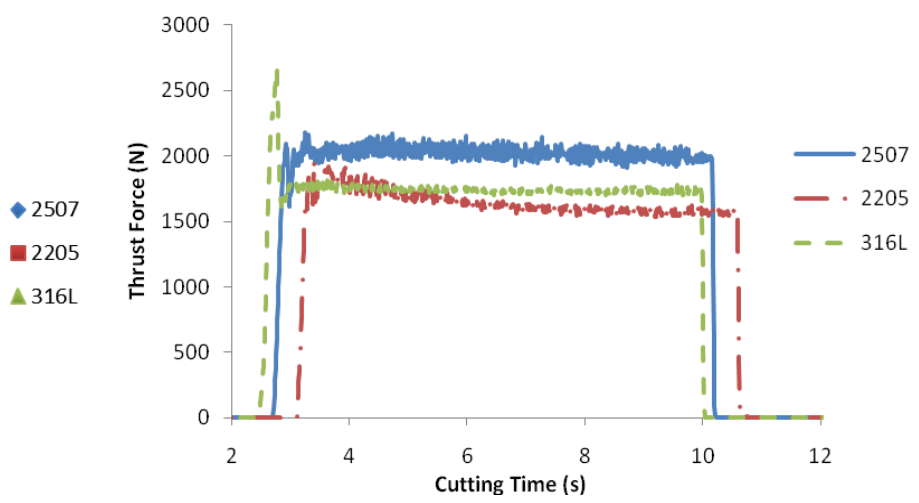

Fig. 14 Thrust forces for different materials (a) average thrust force (b) thrust force profiles for a single hole

(a)

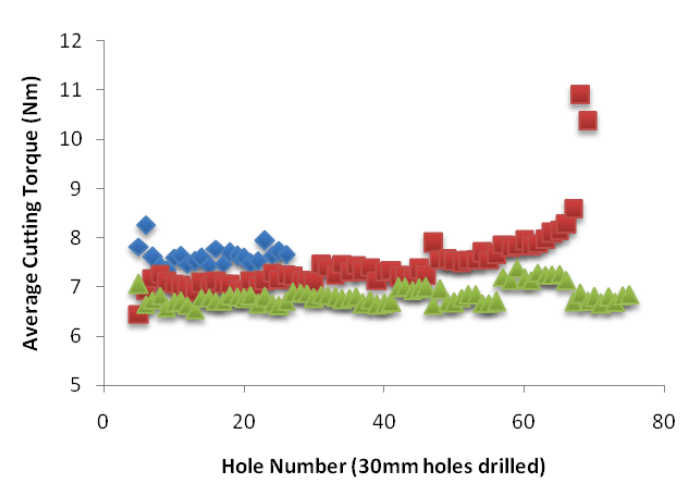

(b)

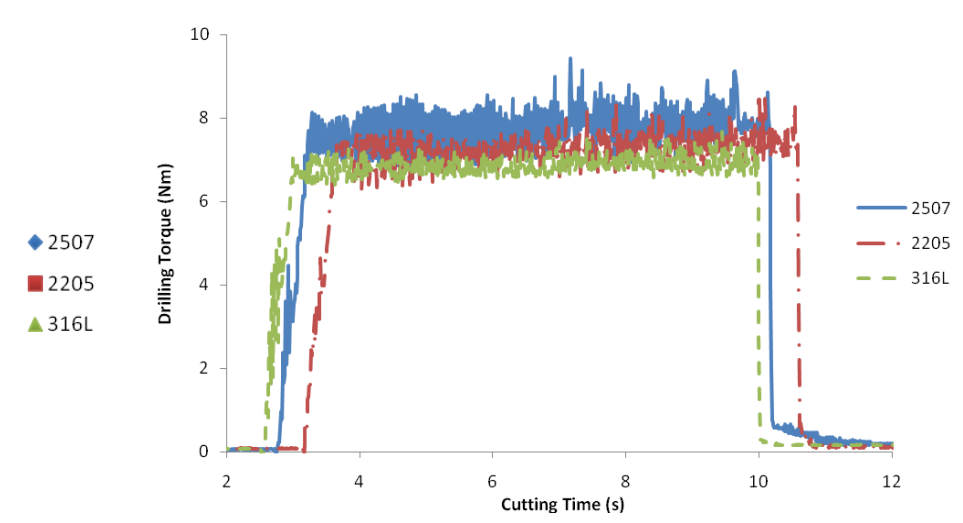

Fig. 15 Drilling torque for different materials (a) average drilling torque (b) drilling torque profiles for a single hole

\subsection{Surface roughness}


Surface profile measurements of the $25^{\text {th }}$ machined holes for the three materials are presented in Fig. 16. The profile of surface for austenite $316 \mathrm{~L}$ is smoother compare to duplex alloys. The worst surface profile was obtained for duplex 2507. The surface roughness $(R a)$ for duplex 2507 , duplex 2205 and austenite $316 \mathrm{~L}$ are $2.067,1.4915$ and $1.1307 \mu \mathrm{m}$ respectively. All these are contributed by higher tool wear, higher built-up-edge and worse chip removal process for duplex 2507.

Fig. 17 plots the variation of surface roughness with number drilled holes for all the three materials. The spread of average surface roughness $\left(R_{a}\right)$ is ranging between 0.5 to $3 \mu \mathrm{m}$. Austenite $316 \mathrm{~L}$ maintains lower fluctuations of Ra compare to that of others. This represents a stable cutting process for austenite 316L. On the other hand, in case of duplex 2507 and 2205 a wider range of fluctuations of $R_{a}$ are noted. This shows less cutting stability.

The combination of tool wear and built-up edge is the most apparent cause for the fluctuation in $R_{a}$. It significantly influences the tolerance and precision machining of duplex materials. The moving average surface roughness plotted against number of drilled holes is shown in Fig 17b. It shows that the trend of $R_{a}$ for both duplex alloys is increasing with the number of drilled holes. The surface textures produced from machining duplex appear rougher by comparison, and weigh heavily on the condition of the drill tool.
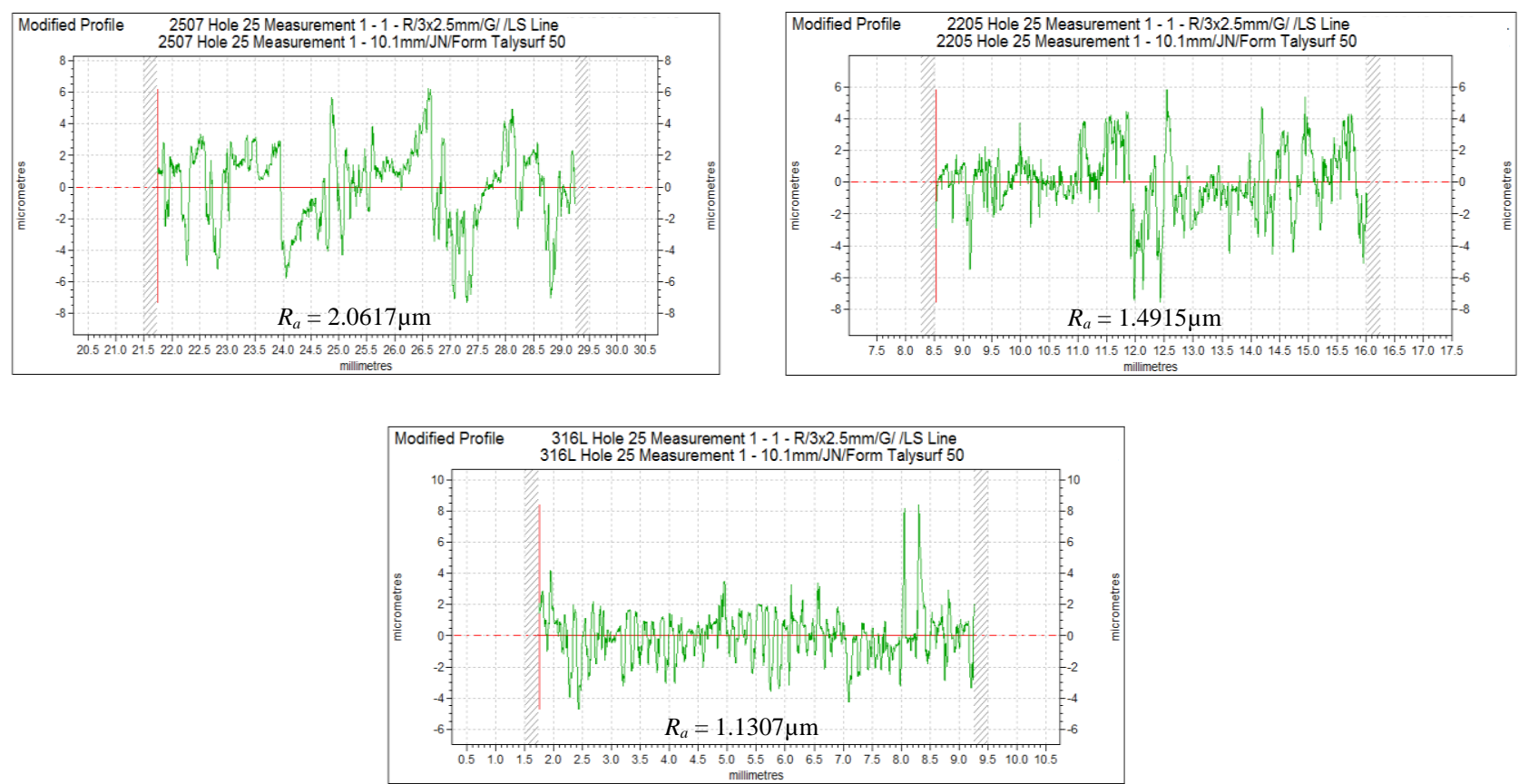

Fig. 16 Surface profile of the $25^{\text {th }}$ drilled hole for different materials 
(a)

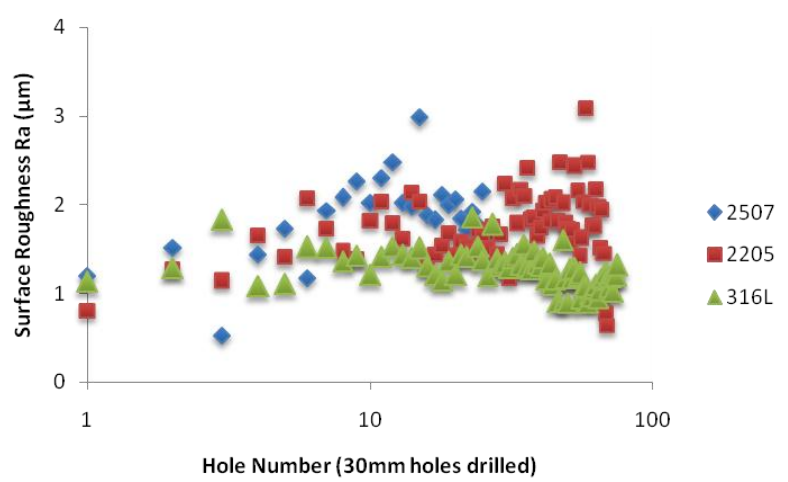

(b)

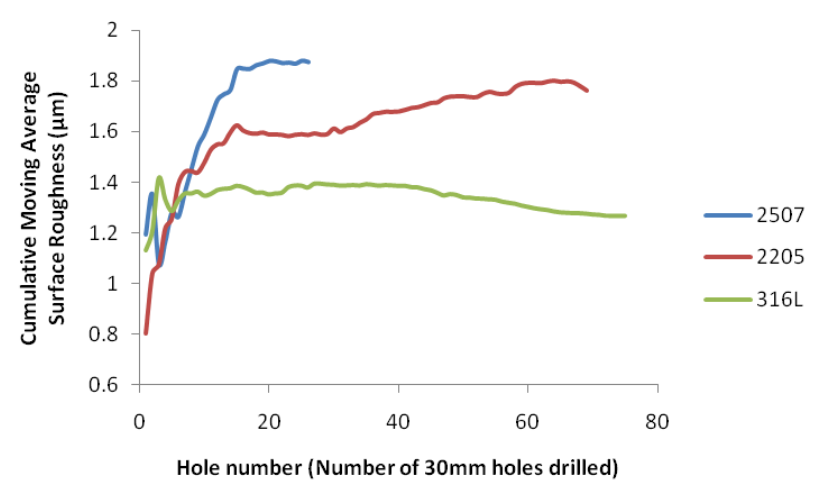

Fig. 17 Variation of surface roughness with the number of drilled holes (a) average surface roughness (b) cumulative moving average

During deformation of the material through working, the two phases are jointly modified but due to their existing a difference in the relative hardness and tensile strength of the phases the distribution of strains does not remain uniform $[10,16]$. Strain concentrations appear in the softer ferrite phase, which can lead to a cracking, grain boundary and inter-phase sliding. Each phase also possesses a different thermal expansion coefficient and so plastic deformation is possible in the absence of applied loads as a consequence of pure thermal cycling surpassing the elastic limit of one or both phases [29]. These phenomena are significant with respect to machining where elevated temperatures and high strain rates are experienced. Thus, worse surface integrity is expected during machining duplex alloys.

\section{Conclusion}

Machinability tests were conducted of duplex 2507 and duplex 2205 and austenite 316L side by side. The machining behaviour of these materials is compared. It is clear that austenite 316L show better machinability compare to that of duplex alloys. . In general, the machinability of duplex is poor compared to other grades of stainless steel resulting primarily from the high strength of the alloy but being exacerbated by a lack of non-metallic inclusions and the low carbon content. Among the duplex alloys, the second generation duplex alloy showed worst machinability. The conclusions from the presented work are as follows.

- Adhesion and abrasion were the most common wear mechanisms found on the flank and rake face sections. Adhesion was found more damaging on the flank. Both duplex alloys 2507 and 
2205 experienced a higher tendency to built-up edge compare to that of austenite 316L. This initiates adhesion wear.

- The chisel edge area responsible for surface penetration saw a larger amount of wear on the duplex tools in comparison to austenite 316L. However, a higher thrust load applied during surface penetration in drilling austenite $316 \mathrm{~L}$.

- Flute damage on drill tools was found for duplex 2507 and 2205. The fracture occurred on the carbide drill tool was brittle. The tool with excessive flute damage was unable to withstand excessive torque and poor chip evacuation. No flute damage was noted during drilling austenite $316 \mathrm{~L}$.

- Among the three materials considered in this study the highest cutting forces and surface roughness are generated during machining duplex 2507 then duplex 2205and lastly austenite 316L. The effect of tool wear and primarily built-up edge results in the trend of these values to be only increasing.

A summary graph of results is presented in Fig. 18.

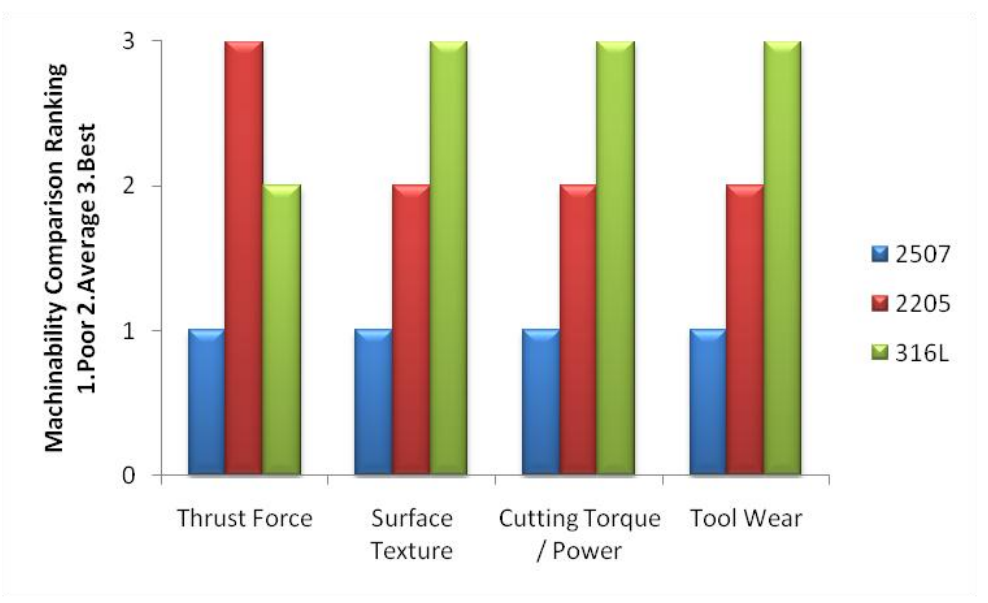

Fig. 18 Machinability summary of results chart

\section{References}

1. Baddoo, N.R., Stainless steel in construction: A review of research, applications, challenges and opportunities. Journal of Constructional Steel Research, 2008. 64(11): p. 1199-1206.

2. Olsson, J. and M. Snis, Duplex -- A new generation of stainless steels for desalination plants. Desalination, 2007. 205(1-3): p. 104-113.

3. Anon, ed. Practical guidelines for the fabrication of duplex stainless steel. 2nd ed. 2009, International Molybdenum Association. 
4. Nilsson, J.O., Super duplex stainless steels. Materials science and technology, 1992. 8(8).

5. Toor, I.-u.-H., P.J. Hyun, and H.S. Kwon, Development of high Mn-N duplex stainless steel for automobile structural components. Corrosion Science, 2008. 50(2): p. 404-410.

6. Smith, C., Why use duplex stainless steel?, in The Fabricator. 2007, FMA Communications Inc: thefabricator.com.

7. Sieurin, H. and R. Sandstrom, Materials Science and Engineering A, 2006. 418: p. 250-256.

8. Cabrera, J., et al., Hot deformation of duplex stainless steel. Materials Processing Technology, 2003: p. 321-325.

9. Saeid, T., et al., Effect of friction stir welding speed on the microstructure and mechanical properties of a duplex stainless steel. Materials Science and Engineering: A, 2008. 496(1-2): p. 262-268.

10. Siegmund, T., E. Werner, and F.D. Fischer, On the thermomechanical deformation behavior of duplex-type materials. Journal of the Mechanics and Physics of Solids, 1995. 43(4): p. 495-532.

11. Dolinsek, S., Work-hardening in the drilling of austenitic stainless steels. Journal of Materials Processing Technology, 2003. 133(1-2): p. 63-70.

12. Jiang, L., et al., Comparison of grindability of HIPped austenitic 316L, duplex 2205 and super duplex 2507 and as-cast 304 stainless steels using alumina wheels. Journal of Materials Processing Technology, 1996. 62(1-3): p. 1-9.

13. O'Sullivan, D. and M. Cotterell, Machinability of austenitic stainless steel SS303. Journal of Materials Processing Technology, 2002. 124(1-2): p. 153-159.

14. Paro, J., H. Hänninen, and V. Kauppinen, Tool wear and machinability of HIPed P/M and conventional cast duplex stainless steels. Wear, 2001. 249(3-4): p. 279-284.

15. Shao, H., L. Liu, and H.L. Qu, Machinability study on 3\%Co-12\% Cr stainless steel in milling. Wear, 2007. 263(1-6): p. 736-744.

16. Ciftci, I., Machining of austenitic stainless steels using CVD multi-layer coated cemented carbide tools. Tribology International, 2006. 39(6): p. 565-569.

17. Voronenko, B., Austenitic-ferritic stainless steels: A state-of-the-art review. Metal Science and Heat Treatment, 1997. 39(10): p. 428-437.

18. Horvath, W., et al., Microstructures and yield strength of nitorgen alloyed super duplex steels. Acta Materialia, 1997. 45(4): p. 1645-1654.

19. Pellegrini, G., G. Caprio, and R. Pacagnella, Drilling operations on duplex stainless steels: tool wear analysis. Metallurgia Italiana, 1999. 91(5): p. 23-30. 
20. Bouzid Saï, W., N. Ben Salah, and J.L. Lebrun, Influence of machining by finishing milling on surface characteristics. International Journal of Machine Tools and Manufacture, 2001. 41(3): p. 443-450.

21. Jin, L.-Z. and R. Sandström, Machinability data applied to materials selection. Materials \& Design, 1994. 15(6): p. 339-346.

22. Carlborg, C., Machinability of duplex stainless steel. Proceedings of duplex stainless steel, 1991. 1(1): p. 683-96.

23. Caprio, G., R. Pacagnella, and G. Pellegrini, Machinability of duplex stainless steel: Cutting parameters and economics of the process. Eurometal working, 1996. 5.

24. Bordinassi, E.C., et al., Surperficial integrity analysis in the super duplex stainless steel after turning. Journal of Achievements in Mechanical and Manufacturing Engineering, 2006. 18(12).

25. M'Saoubi, R. and H. Chandrasekaran, Role of phase and grain size on chip formation and material work hardening during machining of single and dual phase steels. Ironmaking \& Steelmaking, 2004. 31(3): p. 258-264.

26. Williams, J.E. and E.C. Rollason, Metallurgical and Practical Machining Parameters Affecting Built-up Edge Formation in Metal Cutting. Journal of the Institute of Metals, 1970. 98: p. 144-159.

27. Williams, R.A., A STUDY OF THE BASIC MECHANICS OF THE CHISEL EDGE OF A TWIST DRILL. International Journal of Production Research, 1970. 8(4): p. 325-343.

28. HONG, et al., Analysis of drill failure modes by multi-sensors on a robotic end effector. Vol. 118. 1996, New York, NY, ETATS-UNIS: American Society of Mechanical Engineers.

29. Silberschmidt, V.V. and E. Werner, Analysis of thermal residual stresses in duplex-type materials. Computational Materials Science, 1999. 16(1-4): p. 39-52. 